\title{
МОДЕЛЬ ПСИХОЛОГИЧЕСКОЙ ГОТОВНОСТИ СПОРТСМЕНОВ РАЗНЫХ ВОЗРАСТОВ К ТРЕНИРОВОЧНОЙ И СОРЕВНОВАТЕЛЬНОЙ ДЕЯТЕЛЬНОСТИ
}

\section{MODEL OF PSYCHOLOGICAL READINESS OF ATHLETES DIFFERENT AGES FOR TRAINING AND COMPETITIVE ACTIVITIES}

\section{Raikov \\ V. Vysotskaya \\ E. Kolmakova}

Summary: The article considers the psychological readiness of athletes of different specializations at different stages of training as a structure that includes motivational, intellectual, emotional-volitional, psychomotor and communicative components. Each component assumes its own content, which is the subject of diagnostics and assumes its own development programs. We paid more attention to the motivational, emotional-volitional and intellectual components with examples in the training of martial artists.

Keywords: psychological training, psychological readiness of athletes, sports motivation, tactical thinking, volitional competence, psychoactive features, sports communication.
Райков Виктор Кириллович

Директор, КГБУ «Спортивная школа олимпийского резерва имени Б.Х. Сайтиева»

sdushor_pr@mail.ru

Высочкая Вера Александровна

Психолог, КГБУ «Спортивная школа олимпийского резерва имени Б.X. Сайтиева» verafry@yandex.ru

Колмакова Елена Георгиевна

Проректор, КГАУ ДПО «Красноярский краевой институт повышения квалификации работников физической культуры и спорта» elena-kolmakova@mail.ru

Аннотация: Психологическую готовность спортсменов разных специализаций на разных этапах подготовки представим как структуру, включающую мотивационный, интеллектуальный, эмоционально-волевой, психомоторный и коммуникативный компоненты. Каждый компонент предполагает свое содержание, которое служит предметом диагностики и предполагает свои программы развития. Уделили большее внимание мотивационному, эмоционально-волевому и интеллектуальному компонентам с примерами в подготовке спортсменов-единоборцев.

Ключевые слова: психологическая подготовка, психологическая готовность спортсменов, спортивная мотивация, тактическое мышление, волевая компетентность, психомоторные особенности, спортивная коммуникация.
$\Pi$ сихологическая подготовка в спорте делает свой вклад в победу и в самый лучший результат, который возможен через наиболее полную реализацию технико-тактических и функциональных возможностей спортсмена. Управление психологической подготовкой предполагает систему мер и связано с задачей разработки модели психологической готовности спортсменов разных возрастов к тренировочной и соревновательной деятельности. С одной стороны, ориентация на модельные характеристики спортсменов структурирует психодиагностику и позволяет адекватную корректировку содержания тренировочного процесса на разных его этапах. С другой стороны, в основном учитываются характеристики специальной физической и технической подготовленности. В то время как до сих пор, не достаточно разработан психологический аспект. Отсутствие комплексной оценки состояния психологической готовности спортсменов, системной программы психологической подготовки, фрагментарность обследований не способствует правильной оценке психологической и функциональной подготовленности. Данная статья главной целью представляет попытку описать характеристики компонентов психологической готовности спортсменов разных специализаций на разных этапах подготовки как структуру [1].

Психологическая подготовка направлена на формирование и развитие психических процессов и качеств личности спортсменов, необходимых для успешной тренировочной деятельности и результативного выступления на соревнованиях. Психологическая подготовка - это обширный круг действий всех участников спортивной деятельности (тренеров, спортсменов, спортивных врачей, спортивных менеджеров, методистов и родителей). Психологическая готовность спортсмена - это такое его состояние, которое обеспечено в результате подготовки, и которое позволяет достигнуть высоких результатов в соревновательной деятельности [4].

Каждый вид спорта предъявляет свои специфические требования к физическому развитию и способностям спортсмена. Программы подготовки и обеспечения готовности спортсменов в разных видах спорта отличают- 
ся, особенно в своей технико-тактической части. Содержание показателей, характеризующих психологическую готовность спортсменов тоже отличается. В таком случае нам представляется, что определение комплексной объективной оценки подготовленности спортсменов как системы, даст возможность судить о состоянии спортсмена в конкретное время, определить ведущие факторы, за счет которых достигнуто данное состояние и наметить основное направление в дальнейшей подготовке. Необходимое условие комплексной объективной оценки подготовленности спортсменов заключается в определении информативных критериев, имеющих высокие корреляционные связи со спортивным результатом, а также между изучаемыми отличительными признаками, и характеризующих отдельные стороны подготовленности спортсменов.

В период увлечения моделированием и системными теориями в науке (в 60-80-е годы прошлого столетия) и перед психологией была поставлена задача определить модельные характеристики спортсмена для конкретного вида спорта по характеристикам психических процессов, особенностям свойств нервной системы и свойств личности. В.К. Сафонов приводит историческую справку, про исследования модельных характеристик [11]. На протяжении двух олимпийских циклов, включающих шесть Олимпиад, множество чемпионатов мира и континентов, под эгидой Всемирной ассоциации психологов спорта (The International Society of Sport Psychology - ISSP) финалисты соревнований обследовались по единому банку методик. Однако полученные результаты так и не позволили сформулировать модель идеальной личности спортсмена для конкретного вида спорта. Анализ личностных особенностей спортсменов международного уровня не позволил говорить о типичности «личностного профиля» чемпиона.

Качества личности в отличие от личностных свойств формируются в процессе социализации спортсмена как в спорте, так и в остальных сферах жизнедеятельности. В процессе занятия спортом, по мере роста спортивного мастерства, накопления опыта тренировочной и соревновательной деятельности у спортсмена вырабатываются индивидуальные приемы организации своей жизни. Занятия спортом становятся образом жизни, системообразующим фактором жизни спортсмена.

Данные Всемирной ассоциации психологов спорта о личностных особенностях спортсменов свидетельствуют о существенных различиях в уровнях выраженности личностных качеств. Обследование высококвалифицированных спортсменов позволило выделить наиболее характерные особенности их личности - высокая эмоциональная устойчивость, уверенность в себе, сознательность, самостоятельность, склонность к риску, само- контроль, общительность (Киселев, 1987) [3].

Представляется обоснованным говорить об общих (неспецифических) проявлениях личности, обуславливающих успех в спорте, а не в конкретном виде спорта. К числу таковых в первую очередь относятся психогенные особенности спортсмена, обуславливающие высокую чувствительность к восприятию нюансов выполнения спортивной деятельности: сензитивность; тревожность; рефлексивность (активность в преодолении препятствий). Успешность же спортивной деятельности обуславливается совокупностью социогенных особенностей личности: самостоятельностью, эмоциональной устойчивостью (Ильин и др., 1989).

Имеющиеся исследования личностных профилей спортсменов высокого уровня в игровых и индивидуальных видах также свидетельствует о более выраженном проявлении у успешных спортсменов эмоциональной устойчивости, самоконтроля, независимости (Сопов, 2010). Интересно, что в организационной психологии перечень качеств личности успешного руководителя и эффективного спортсмена полностью совпали. Этим примером можно проиллюстрировать идею неспецифичности качеств личности выдающегося профессионала, в нашем случае спортсмена, обусловливающих успешность профессиональной спортивной деятельности.

При описании модели психологической готовности спортсменов важно ясно понимать специфику видов спорта. Недостаточный уровень психологической подготовленности спортсменов лимитирует их эффективность и надежность соревновательной деятельности, ограничивает результативность их выступлений.

Психологическая готовность как специализированные (специфические) психофизиологические возможности (или компетентности) спортсмена применительно к требованиям конкретного вида спортивной деятельности, проявляется через саморегуляцию личности. В разделяемом нами понимании Б.П. Яковлева, саморегуляция - это процесс произвольного управления спортсменом своей деятельностью (психомоторной, коммуникативной, интеллектуальной, эмоциональной, волевой), обусловленный спецификой подготовки (тактико-технической, физической, психологической, интегральной) в различных видах спорта, оказывающий прямое или опосредованное влияние на уровень подготовленности и его спортивных результатов[14].

На сегодняшний день стало бесспорным, что успех в спорте напрямую зависит от психологической готовности. Анализ современных исследований в спортивной психологии показал, что наиболее последовательное и 
систематическое изучение психологических требований к личности спортсмена в основном проводится по трем ее проявлениям - воле, интеллекту и эмоциям [1].

Рассмотрим модель психологической готовности как систему, где мотивационный, интеллектуальный, эмоционально-волевой, психомоторный и коммуникативный компоненты психологической готовности спортсменов представлены с учетом вида спорта и этапа спортивной карьеры.

Спортивная мотивация представляет собой сложное психическое состояние личности спортсмена. Возникновение спортивной мотивации у человека обусловлено воздействием на него окружающей среды, то есть содержанием самой спортивной деятельности, и ее исполнителей. Так на этапах начальной подготовки велика роль родителей, учителей. Далее центральной фигурой становится тренер. Чем старше спортсмен, тем больше его личный автономный вклад. В процессе развития и функционирования спортивной мотивации степень влияния внешних и внутренних факторов может меняться. Сохранение (устойчивость) спортивной мотивации у спортсмена обусловливается его спортивными достижениями. Спортивная мотивация включает следующие основания: побудительные, базисные, процессуальные. Уровень их сформированности у спортсменов существенно различается. В соревновательной мотивации выделяется два направления: мотивация на достижение успеха и на избегание неудач: соотношение их на разных этапах спортивного совершенствования может быть различной $[1,6]$.

В спортивной мотивации выделяется два направления: тренировочная и соревновательная мотивация. Преобладание той или иной направленности мотивации зависит от ряда личностных качеств и оказывает существенное влияние на спортивные достижения спортсмена. На начальном этапе преобладает тренировочная мотивация. На этапе спортивной специализации тренировочная и соревновательная мотивации выражены в одинаковой степени. На этапе спортивного совершенствования в структуре спортивной мотивации преобладает соревновательная. Учет этих тенденций является необходимым в работе тренера со спортсменами.

Выделяют следующие типы отношений к занятиям спортом (Г.Д. Бабушкин, Е.Г. Бабушкин): отрицательное, безразличное, положительное-аморфное, положительное - активно-действенное. Из приведенных типов отношений положительное - активно-действенное имеет самый наименьший процент от общего числа. В то же самое время именно он считается самым действенным типом с выраженной устойчивой мотивацией спортивной деятельности, обусловливающей результативность.
Наибольшее количество отказов от занятий спортом отмечается в группах с отрицательным и безразличным уровнем включенности в занятия.

Диагностика мотивации в спорте один из труднейших вопросов организации психологического обеспечения спортивной деятельности. Это связано и с отсутствием единого взгляда в психологии на то, что такое мотивация; со сложностью самого процесса мотивации, включающего в себя разные, зачастую разнонаправленные мотивы, с дефицитом методик, исследующих мотивацию во всей ее полноте и динамике. В психодиагностике мотивации выделяют три основные группы методов: прямые методы (беседа, наблюдение, анкеты), косвенные методы (личностные опросники) и проективные методы.

При изучении готовности спортсмена принципиально ценным является понимание двух особенностей мотивационной сферы в процессе занятия спортом: первая - цель спортивной деятельности и устойчивость-изменчивость мотивационной сферы в процессе занятия спортом; вторая - динамика мотивационных установок в ситуации спортивного соревнования.

По мнению В.К. Сафонова, осознание цели того, что делает спортсмен здесь и сейчас, к какому старту готовится - одно из важнейших составляющих именно психологической подготовки спортсмена. Применительно к спортивной деятельности под осознанием автор имеет в виду вербализацию цели спортивной деятельности и критериев ее достижения. Цель спортивной деятельности должна определяться как на сезон, так и на конкретную тренировку, для членов сборных команд страны на олимпийский цикл.

В контексте обсуждения мотивации с учетом возрастных особенностей физического и психического развития выделим следующие этапы:

1 - половой идентификации (4-6 лет);

2 - полового созревания (11-14 лет - девушки, 12-

15 лет - юноши);

3 - половой зрелости (16-18 лет - девушки, 17-19

лет - юноши)

4 - зрелой личности (22-24 года).

Каждый этап характеризуется изменениями, перестройкой функционирования соматических и психических процессов. Периоды перестройки в свою очередь характеризуются неустойчивостью и изменчивостью биохимических, нейрофизиологических, физиологических и психических процессов. В возрасте 4-7 лет дети не могут осуществлять произвольную регуляцию тонкой психомотрики. В 10-15 лет у юношей и девушек трудности в усвоении сложных координационных движений, в 15-19 лет - неустойчивость психической сферы, пре- 
жде всего эмоциональной. У спортсменов старше 22-23 лет формируется личностный смысл того, чем они занимаются, то есть мотивы автономизируются и внутренняя мотивация становится актуализированной.

Преодоление в детском спорте каждого из кризисов развития занимает около года. В этот период приостанавливается рост спортивных результатов, но продолжается формирование мотивации. От успешности преодоления психологических кризисов развития (детских кризисов) зависит дальнейшая судьба спортсменов, их мотивационная компетентность.

Таким образом, мотивация идеального спортсмена им осознается, она в большей степени внутренняя, и спортсмен может ее регулировать. В модели психологической готовности спортсмена преобладают характеристики ориентации на смыслы содержания конкретного вида спорта, выражена ориентация на достижение результатов, мотивы устойчивы, осознанны смыслы и сформулированы цели.

Интеллектуальный компонент в описании модели психологической готовности, как системы, традиционно представлен особенностями восприятия, внимания, памяти и мышления спортсмена. Мышление является ведущим психическим процессом в тактической деятельности спортсмена. Мышление спортсмена, задействованное непосредственно в ходе решения соревновательных ситуаций, называется тактическим или оперативным мышлением. Наиболее важно мышление в игровых видах спорта и в единоборствах, где имеет место множество соревновательных ситуаций, требующих оперативного разрешения.

Тактическое мышление протекает неразрывно от действий. Спортсмен анализирует возникшую ситуацию и осуществляет непосредственные действия. Правильные действия находятся не путем предварительного продумывания, а в самом действии. Тактическое мышление имеет наглядно-образный характер. При решении тактических задач мышление основано на наглядных чувственных образах и явлениях. Ситуативный характер мышления проявляется в том, что мышление спортсмена протекает на фоне меняющихся характеристик. Тактическое мышление представляет собой сложную умственную деятельность, характеризующуюся быстротой, гибкостью, самостоятельностью, глубиной, широтой и критичностью. Спортсмен выбирает из множества знакомых приемов, по его мнению, наиболее подходящий для этой ситуации. Действия спортсмена определенным образом выстраиваются в последовательности с предвидением конечного результата. Тактическое (оперативное) мышление спортсмена опирается на память, на ее разновидности - оперативную, кратковременную.
Спортсмен учитывает только, что произошедшее и на этой основе совершает новые действия. Так же тактическое мышление характеризуется проявлением интуиции. Интуиция - это протекание мыслительных процессов в свернутой форме, когда осознается лишь конечный результат, большая часть действий выполняется без их осознавания. Осмысливание выполняемых действий спортсменом происходит уже после их совершения, после соревнования. Интуитивные действия совершаются на основе богатого соревновательного опыта, глубоких специальных знаний, умений наблюдать за действиями спортсменов на соревновании.

Особую роль в тактическом мышлении занимают антиципирующие реакции. Антиципация - предвидение, предвосхищение действий соперника. На основе этого спортсмен выполняет упреждающие действия, выходя победителем ситуации. Предвосхищение действий, тактических комбинаций соперника возможно не только на основе памяти, творческого воображения, мышления, но и на основе учета предшествующих действию признаков. Например, в волейболе при блокировании такими признаками могут быть положение предплечья и кисти бьющей руки, разворот плеча, в единоборствах - положение опорной ноги, положение рук противника.

Успешному решению тактических задач в предстоящем соревновании должно предшествовать предварительное планирование тактических действий. Планирование строится на основе учета информации о противнике и соревновательных условий. Оно носит ориентировочный характер и допускает необходимые изменения по ходу действий.

На степень сложности тактических планов влияют особенности вида спорта. В одних видах спорта, например в легкой атлетике (бег), лыжном спорте, конькобежном спорте тактический план представляет собой график прохождения дистанции. В других видах спорта, например в гимнастике, тактический план строит тренер, предусматривая последовательность выполнения гимнастами упражнений. Более сложным является планирование в единоборствах и спортивных играх, где имеет место детальная разработка командных тактических действий (в звеньях, линиях) с учетом конкретных индивидуальных заданий.

Приведем пример тактического мышления единоборцев. Предварительное тактическое планирование почти всегда имеет вероятностный характер. Это обусловлено тем, что невозможно иметь полную информацию о противнике, его замыслах, условиях состязания. При этом противоборствующая сторона также стремится выиграть поединок, прикладывая к этому усилия. В этой связи реализация тактического плана - это постро- 
ение предположения о тактических замыслах противника в начале поединка, применение приемов с целью замаскировать собственный тактический план действий, и непрерывное решение частных тактических задач, возникающих по ходу борьбы.

Как маркеры тактического мышления единоборцев существенное значение имеют следующие способности и умения спортсмена: умения и навыки, позволяющие быстро решать задачи; умение мыслить в процессе соревнования, критически оценивать собственные решения и действия, умение обобщать и выбирать нужные на данный момент тактические приемы; быстрота мышления, гибкость, глубина и широта мышления.

В процессе выступлений спортсменов на соревнованиях происходит формирование тактического мышления. На принятие решения в спортивной деятельности оказывают влияние следующие факторы: амплуа спортсмена (нападающие и защитники действуют по разному), соревновательный опыт спортсмена, физическая подготовленность спортсмена, возраст спортсмена, свойства нервных процессов и интеллектуальные качества: наблюдательность, сообразительность, предвидение, быстрота и гибкость ума - являются важными факторами в быстроте и правильности принятого решения в спорте. Спортсмены с более высоким интеллектом лучше справляются. В том числе волевые качества: самостоятельность, инициативность, решительность, самообладание.

Итак, в описании системы модели психологической готовности интеллектуальный компонент представлен тактическим мышлением спортсменов, которое является ведущим психическим процессом в обеспечении эффективных результатов. Тактика в спорте - это совокупность применений технических приемов в соответствии с условиями и задачами соревновательной деятельности. Тактика имеет свои особенности в каждом виде спорта. Развитие интеллектуального компонента составляет важную часть психологической подготовки спортсменов.

Проблема воли как высшего психического процесса сознательной регуляции человеком своего поведения и эмоционально-волевые компетентности спортсменов в спортивной психологии занимает внимание многих исследователей и актуальна в практическом смысле. В реализации психологической подготовки понимание воли, ее формирование и развитие для всех субъектов спортивной деятельности видится нам ценным и представляется перспективным.

Считается общепринятым, что развитие волевых качеств является предпосылкой успеха в любом виде спортивной деятельности. Важнейшими волевыми качествами спортсменов и тренеров называют целеустремленность, инициативность, смелость, решительность, выдержка и самообладание. Н.Л. Ильина упоминает исследования о значимости именно волевых и мотивационных аспектов в обеспечении эффективности работы спортивного тренера $[1 ; 11]$.

А.Ц. Пуни, рассуждая о воле в контексте спортивной деятельности, выделяет в волевом акте три компонента, а именно: познавательный (поиск правильного решения, самооценка результатов волевых действий), эмоциональный (самомотивировка, усиление) и исполнительный (физическая регуляция посредством сознательного принуждения). А.Ц. Пуни подробно описал волевые качества спортсменов: целеустремленность, настойчивость и упорство, решительность и смелость, инициативность и самостоятельность, выдержка и самообладание. Самым важным волевым качеством он называл целеустремленность, которая обусловливает все другие волевые качества. В этом качестве стадии волевого процесса по Рубинштейну скорее всего проявлены максимально точно. Идеи А.Ц. Пуни о роли волевых качеств спортсменов и тренеров остаются определяющими центральную линию работы психологов по поводу воли спортсменов и тренеров.

В целостном психическом акте волевой процесс через побуждение оказывается связанным с эмоциями, а через анализ мотивов и следствий - с интеллектуальным процессом. Так Ю. Куль определяет волю как фактор, образующий целостность, соединяющий эмоции и умственные процессы. Опосредующие процессы контроля за действием человек осознает и активно их реализует. Юлиус Куль [2] выделил собственно мотивационные и волевые аспекты мотивационного процесса и рассмотрел мотивацию выбора и мотивацию реализации. Выбор (селекция) одной из возможных альтернатив действия в рамках мотивационного процесса не означает получения продуктивного результата, то есть реализации выбранного варианта действия. Для реализации часто требуется серьезное системное усилие, преодоление, другими словами, такой волевой процесс, где есть контроль за действием, с учетом того, что имеются конкурирующие тенденции, препятствующие реализации выбранного действия.

Спортивная деятельность характеризуется своеобразными эмоциональными состояниями и отношениями, так называемыми «спортивными эмоциями». Они возникают на соревнованиях, в процессе выполнения спортивных действий, разрешения спортивных задач, оказывают влияние на выполняемые действия, на их результативность. Черникова О.В. выделяла специальные спортивные эмоции, способствующие успешному вы- 
ступлению на соревнованиях: спортивное возбуждение, боевое воодушевление, игровое или спортивное увлечение, спортивная злость, чувство спортивной гордости и чести, спортивное соперничество.

В.И. Слободчиков и Е.И. Исаев предлагают относить к волевым только те действия, которые совершаются по необходимости, при недостатке непосредственного побуждения или связаны с преодолением трудностей. Представление о воле как механизме преодоления препятствий довольно часто встречается в психологии. В частности В.В. Андреев, спортивный психолог, развил понятие воли в контексте спортивной деятельности, представив ее как феномен преодоления, как психологическую категорию, систематизирующую субъективный мир спортсмена. Именно в процессе преодоления происходят процессы, катализирующие и детерминирующие развитие сознания, самосознания и поведения спортсмена. Преодоление проявляется в виде мотивационных, эмоциональных, когнитивных, поведенческих и соматических процессов, выступающих для субъекта как психическая деятельность, направленная на преобразование, сублимацию и трансформацию показателей неопределенности, опасности, нужды и недостатков в личностный рост [4;11].

Поиску путей развития воли и эмоциональной компетентности в спортивной психологии уделяется большое внимание. Наши исследовательские и практические интересы связаны с задачами прояснения и осознавания категории воли, волевых и эмоциональных компетенций, содержания волевого акта. Приведем результаты исследования, которое проходит в рамках основных мероприятий проекта федеральной экспериментальной площадки по теме «Реализация кластерной модели подготовки спортивного резерва по вольной борьбе среди женщин в Сибирском федеральном округе» (приказ Минспорта России от 04.05.2018 №430). В этом варианте исследования приняли участие тренеры краевого бюджетного учреждения «Спортивная школа олимпийского резерва имени Б.Х. Сайтиева» (СШОР имени Б.Х. Сайтиева) в количестве 20 человек. Все тренеры работают в единоборствах, стаж от нескольких месяцев до 40 лет. Тренеры получили анкету в виде списка, где им было необходимо выбрать 5 качеств спортсмена-единоборца, самых важных и ценных на их взгляд. Список включает (1) волевые качества (концентрация, сосредоточенность; способность регулировать свои реакции; смыслы, сформулированное спортсменом отношение к трудностям, как к части жизни), (2) эмоциональную зрелость (способность называть свои чувства, переживать их в разных диапазонах, регулировать их), (3) сбалансированную ориентация на хороший результат, на победу, на преодоление себя самого, (4) уверенность в себе (знает себя, есть самоуважение), (5) смыслы и ценности, (6) выносли- вость, (7) жизнестойкость (8) аналитичность, рефлексия, как умение работать с ошибками, (9) креативность и (10) коммуникативную компетентность. Результаты анкетирования представим в таблице 1.

Таблица 1

Представления тренеров об идеальных качествах спортсменов-единоборцев

\begin{tabular}{|l|c|} 
Качества личности спортсмена единоборца & $\begin{array}{l}\text { Количество } \\
\text { выборов (в \%) }\end{array}$ \\
\hline 1.Волевые качества & $90 \%$ \\
\hline 2. Эмоциональная зрелость & $50 \%$ \\
\hline $\begin{array}{l}\text { 3. Сбалансированная ориентация на хороший резуль- } \\
\text { тат, на победу, на преодоление себя самого }\end{array}$ & $60 \%$ \\
\hline 4. Уверенность в себе & $30 \%$ \\
\hline 5. Смыслы и ценности & $45 \%$ \\
\hline 6. Выносливость & $25 \%$ \\
\hline 7. Жизнестойкость & $45 \%$ \\
\hline $\begin{array}{l}\text { 8. Аналитичность, рефлексия, умение работать с с } \\
\text { ошибками }\end{array}$ & $15 \%$ \\
\hline 9. Креативность & $5 \%$ \\
\hline 10. Коммуникативная компетентность & $45 \%$ \\
\hline
\end{tabular}

Мы видим, что самыми популярными стали волевые и эмоциональные компетенции, как самые важные и определяющие победу единоборца.

Тренеру на любом этапе спортивной подготовки, а особенно на начальном, необходимо актуализировать процесс осознания эмоций и переживаний у спортсмена. В спорте эмоционально-волевая компетентность и готовность спортсменов представлена как проблема существует и проявлена в системе исследований [1]. Для спортсмена воля определена как основание сознательной регуляции их профессионального поведения.

Понятие «психомоторика» введено в научный обиход И.М. Сеченовым. Оно подчеркивает зависимость двигательных проявлений человека от психической регуляции. Так, осуществление физических упражнений происходит под контролем сознания, а проявление двигательных качеств требует участия волевого усилия. Поэтому психомоторная сфера человека - это сплав психологических и физиологических механизмов управления движениями, двигательными действиями, отражающихся в проявлении разных психомоторных (двигательных) качеств [7]. Под психомоторными способностями понимается совокупность свойств психики, обеспечивающих точность управления движениями. К ним относятся произвольность двигательных действий, умение различать и воспринимать пространственные, силовые и временные параметры движений, двигательная память, двига- 
тельное воображение.

Психомоторные способности - это сложноорганизованные познавательно-регуляторные системы, в которых в единстве представлены как мотивационные, функциональные, так и операционные компоненты, при этом точность, интенсивность и эффективность управления движениями зависят и существенно определяются уровнем функционирования таких психических процессов, как ощущение и восприятие. Психомоторные процессы представляют собой объективное восприятие человеком всех форм психического отражения, начиная с ощущения и заканчивая сложными формами интеллектуальной активности. В настоящее время можно выделить следующее определение психомоторики: «это основной вид объективизации психики в сенсомоторных, идеомоторных и эмоционально-моторных (в частности, импульсивных) реакциях и актах» [7]. Кроме того, «психомоторика - это разновидность психически обусловленных движений человека, типологически различных в зависимости от строения тела, возраста, пола и т.п.». Во взглядах многих теоретиков и практиков психомоторные способности представляют ядро двигательных способностей, которое выступает как их когнитивно-моторный компонент, включающий сенсомоторные, перцептивные, интеллектуальные и нейродинамические особенности, реализуемые как на произвольном, так и на непроизвольном уровне самоконтроля и саморегуляции движений. Исходя из чего следует, что успешность соревновательной деятельности в значительной степени зависит от уровня развития психомоторных функций, непосредственно участвующих в саморегуляции движений. Психомоторные функции развиваются в процессе спортивной тренировки целенаправленно: становятся более точными и быстрыми те процессы и реакции, которые необходимы для управления движениями в конкретном виде спорта. Если в ходе спортивной тренировки рационально и целенаправленно развивать необходимые психомоторные качества, можно получить дополнительный эффект роста технического мастерства. То есть совершенствование регуляторных функций психомоторики - дополнительный путь повышения результативности в спортивной деятельности.

Психомоторный компонент в готовности спортсмена проявляется как важная и обеспечивающая спортивную победу функция.

Коммуникативная компетентность как профессионально-личностное качество, позволяющее спортсмену адекватно ориентироваться в условиях тренировки и командной игры, требует продуктивного включения в ситуации общения и взаимодействия, адекватного принятия тренерских инструкций и игрового взаимодействия с партнерами, социальным окружением, болель- щиками.

Спецификой коммуникации в спорте является возникновение психического контакта между всеми его участниками. Основной целью общения и коммуникации в спорте является взаимный обмен информацией и взаимное влияние всех участников. Будем рассматривать коммуникативный компонент психологической готовности спортсменов на примерах содержания общения в спорте.

Коммуникация в спорте, как и везде, реализуется с помощью вербальных (речевых) и невербальных средств. Например, при помощи речевых средств общения тренер объясняет, отдает распоряжения и оценивает действия спортсменов. А спортсмены общаются во время игры с целью повышения эффективности своего взаимодействия. Для игровых видов спорта характерно использование кратких речевых сообщений. К невербальным средствам общения относятся жесты, мимика, взгляды и движения, которые также широко распространены в игровых видах спорта. Во время игры невербальные средства общения несут огромную смысловую нагрузку для членов команды, позволяя им давать друг другу важную информацию о своих намерениях.

Содержание, уровень и особенности коммуникации спортсменов зависят от стажа совместной деятельности, знаний друг о друге, совпадения представлений о поставленной задаче, статуса спортсменов и их роли в команде, физической и технико-тактической подготовленности, межличностных отношений в команде.

Больше всего изучена коммуникативная компетентность спортсменов игровых и командных видов, хотя проблема коммуникативной компетентности относится в равной степени ко всем видам спорта и спортивным дисциплинам.

На начальном этапе спортивной подготовки у спортсмена много задач и потенциальных перспектив относительно развития своей способности быть эффективным коммуникатором и уметь общаться. Во-многом на начальном этапе развитие коммуникативных компетенций спортсмена зависят от родителей и тренера. На этапах спортивного мастерства спортсмену уже предъявляют высокие требования, когда его коммуникативные способности и умения становятся частью общего содержания его спортивной жизни. Навыки эффективной публичности для спортсмена важны и актуальны на соревнованиях самого высокого уровня.

Коммуникативная компетентность спортсмена складывается из умений и компетенций самопрезентации, вступления и поддержания контакта, регулирования 
конфликтов. Лидер и команда, тренер и спортсмен, родители - особые коммуникативные ситуации в спорте. Целью повышения уровня коммуникативной компетентности спортсменов является обновление и обогащение их теоретических и практических знаний в спортивной сфере в соответствии с постоянно повышающимися требованиями и для поддержания уровня их квалификации, достаточного для реализации профессиональных задач.

Различают четыре основных коммуникативных стиля: ритуальный, императивный, манипулятивный и гуманистический. Коммуникативная компетентность предполагает овладение навыками эффективного влияния и противостояния негативному влиянию, например манипуляции. По сути, готовность спортсмена связана с коммуникативной компетентностью, развитие и укрепление которой представляет задачу вне зависимости от вида спорта.

Итак, мы рассмотрели психологическую готовность спортсменов разных специализаций на разных этапах подготовки как структуру, включающую мотивационный, интеллектуальный, эмоционально-волевой, психомоторный и коммуникативный компоненты. Каждый компонент предполагает свое содержание, которое служит предметом диагностики и предполагает свои программы развития. Мы уделили большее внимание мотивационному, эмоционально-волевому и интеллектуальному компонентам с примерами в подготовке спортсменов-единоборцев. Описание модели и построение структуры психологической готовности с учетом возрастных особенностей и специфики вида спорта продолжает оставаться актуальной темой для исследований и прагматических практик.

1. Ильин Е.П. Психология спора. СПб.: Питер, 2017. - 352 с.

\section{ЛИТЕРАТУРА}

2. Куль Ю., Шторх М. Сила собственного «Я». Семь психогимнастик для бессознательного. Изд. Гуманитарный центр, $2015,-324$ с.

3. Капилевич М.В., Давлетьярова В.К., Кошельская Е.В., Бредихина Ю.П. Андреев В.И. Физиологические методы контроля в спорте, Томск: Издательство Томского политехнического университета, 2009, - 172 с.

4. Марков К.К., Лебединский В.Ю. Формирование психомоторных качеств в современном спорте: теоретические и методологические проблемы / Психология спорта, №4, июнь, 2014г, - 54-56 с.

5. Малкин В.Р. Управление психологической подготовкой в спорте / В.Р. Малкин. - М., 2008.

6. Никандров В.В. Психомоторика: учебное пособие / В.В. Никандров. - СПб.: Речь, 2004. - 104 с

7. Психология личности спортивного тренера. Монография / Л. Серова, Р. Терехина. М.: Спорт, 2019. - 128 с.

8. Психология физической культуры: учебник / под ред. Б.П. Яковлева, Г.Д. Бабушкина. - М.: Спорт, 2016.- 624 с.

9. Практикум по спортивной психологии, под ред. Волкова И.П. СПб.:Питер, 2002. - 284 с.

10. Рубинштейн С.Л. Основы общей психологии. СПб.:Питер, 2010.

11. Сафонов В.К. Психология спортсмена: слагаемые успеха — М.: Спорт, 2018.- 288 с.

12. Хекхаузен Х. Мотивация и деятельность. - 2-е изд. - СПб.:Питер; М.: Смысл, 2003.- 860 с.

13. Френкин Р. Мотивация поведения: биологические, когнитивные и социальные аспекты / 5-е изд. - СПб.:Питер, 2003.- 651 с.

14. Яковлев Б.П. Основы спортивной психологии: учебное пособие/- 2-у изд. стереотип. - М.: Советский спорт, 2014.- 208 с.

( Р Райков Виктор Кириллович (sdushor_pr@mail.ru), Высоцкая Вера Александровна (verafry@yandex.ru), Колмакова Елена Георгиевна (elena-kolmakova@mail.ru).

Журнал «Современная наука: актуальные проблемы теории и практики» 